\title{
Eco-efficient butanol separation in the ABE fermentation process
}

DOI:

10.1016/j.seppur.2016.12.008

\section{Document Version}

Accepted author manuscript

Link to publication record in Manchester Research Explorer

\section{Citation for published version (APA):}

Patracu, I., Bîldea, C. S., \& Kiss, A. A. (2017). Eco-efficient butanol separation in the ABE fermentation process. Separation and Purification Technology, 177, 49-61. https://doi.org/10.1016/j.seppur.2016.12.008

\section{Published in:}

Separation and Purification Technology

\section{Citing this paper}

Please note that where the full-text provided on Manchester Research Explorer is the Author Accepted Manuscript or Proof version this may differ from the final Published version. If citing, it is advised that you check and use the publisher's definitive version.

\section{General rights}

Copyright and moral rights for the publications made accessible in the Research Explorer are retained by the authors and/or other copyright owners and it is a condition of accessing publications that users recognise and abide by the legal requirements associated with these rights.

\section{Takedown policy}

If you believe that this document breaches copyright please refer to the University of Manchester's Takedown Procedures [http://man.ac.uk/04Y6Bo] or contact uml.scholarlycommunications@manchester.ac.uk providing relevant details, so we can investigate your claim.

\section{OPEN ACCESS}




\section{Eco-efficient butanol separation in the ABE fermentation process}

3 Iulian Patraşcu, ${ }^{1}$ Costin Sorin Bîldea, ${ }^{1}$ Anton A. Kiss, ${ }^{2,3 *}$

$4{ }^{1}$ University "Politehnica” of Bucharest, Polizu 1-7, 011061 Bucharest, Romania

${ }^{2}$ AkzoNobel Research, Development \& Innovation, Process Technology SRG, Zutphenseweg

10, 7418 AJ Deventer, The Netherlands.E-mail:Tony.Kiss@akzonobel.com

${ }^{3}$ Sustainable Process Technology Group, Faculty of Science and Technology, University of

*Corresponding author: TonyKiss@gmail.com, Tel: +31263669420

\section{Keywords}

Downstream processing, distillation, dividing-wall column, optimal design, process control

\section{Highlights}

- Energy efficient downstream processing in the acetone-butanol-ethanol (ABE) process

- Cost effective distillation process for butanol separation and purification

- Optimal process design including heat-integration, still robust and controllable

\section{Abstract}

Butanol is considered a superior biofuel, as it is more energy dense and less hygroscopic than the more popular ethanol, resulting in higher possible blending ratios with gasoline. However, the production cost of the acetone-butanol-ethanol (ABE) fermentation process is still high, mainly due to the low butanol titer, yield and productivity in bioprocesses. The conventional recovery by distillation is an energy-intensive process that has largely restricted the economic production of biobutanol. Other methods based on gas stripping, liquid-liquid extraction, adsorption, and membranes are also energy intensive due to the bulk removal of water.

This work proposes a new process for the butanol recovery by enhanced distillation (e.g. dividing-wall column technology) using only few operating units in an optimized sequence to reduce overall costs. A plant capacity of $40 \mathrm{ktpy}$ butanol is considered and purities of 99.4 \%wt butanol, $99.4 \%$ wt acetone and $91.4 \%$ wt ethanol. The complete downstream processing was rigorously simulated and optimized using Aspen Plus. The enhanced process is effective in terms of eco-efficiency (1.24 kWh/kg butanol, significant lower costs and emissions) and can be readily employed at large scale to improve the economics of biobutanol production. 


\section{1. Introduction}

2 Biobutanol is an alternative fuel (from the group of bioalcohols) with characteristics similar to petro-fuels. Compared to the more popular ethanol, butanol enjoys lower water miscibility, flammability, and corrosiveness, while having also the advantage of being able to directly replace gasoline in car engines without needing any modifications (Abdehagh et al., 2014). Moreover, it can be produced from a wide variety of waste biomass feedstock that does not compete with food, so it avoids food versus fuel issues. Industrially, the most widely used microorganisms for acetone-butanol-ethanol (ABE) fermentation are anaerobic bacteria such as the solventogenic Clostridia, including Clostridium acetobutylicum as well as Clostridium beijerinckii (Tashiro et al., 2013). However, the ABE production via fermentation is facing great challenges due to the very low concentration ( $<3 \%$ wt butanol) and yield owing to the severe butanol toxicity to microorganisms. One way to solve the problems is the modification of microorganisms for $\mathrm{ABE}$ fermentation by genetic engineering (to keep them alive and active under higher butanol concentrations), leading to increase of productivity, yield and concentration and thus reducing the production costs (Green, 2011). But this is an unrealized long term goal, and even if the modification of microorganisms becomes a reality, product separation and purification will still remain a critical challenge (Huang et al., 2014). The other approach is the development of more efficient downstream processes for butanol recovery.

Lately, the $\mathrm{ABE}$ fermentation process has received renewed attention, and the developments resulted in somewhat higher butanol concentrations, less fermentation by-products and higher volumetric productivities during fermentation (Xue et al., 2013). However, these still have to be matched by a downstream processing route that is less energy intensive and can reduce the separation costs (Xue et al., 2013; 2014; Huang et al., 2014; Kiss et al., 2015). Therefore, it is essential to find an eco-efficient separation process - with enhanced economic performance and reduced ecological impact - for the recovery of butanol, during or after fermentation. Several review papers describe the main separation techniques used, such as: distillation, adsorption, gas stripping, vacuum flash, liquid-liquid extraction (LLX), reverse osmosis (RO), perstraction, pervaporation, and hybrid separations (Liu et al., 2005; Huang et al., 2008; Vane, 2008; Kraemer et al., 2011; van der Merwe et al., 2013; Mayank et al., 2013; Abdehagh et al., 2014; Kujawski et al., 2014; Kujawska et al., 2015; Errico et al., 2015). While many of these technologies are still in the research and development phase, distillation remains an industrially-proven technology with significant potential to improve its energy efficiency by process intensification (Kiss, 2013, 2014; Blahusiak et al., 2016). However, the use of distillation for butanol recovery is considered too demanding in terms of energy requirements, 
1 using up to $220 \%$ of the energy content of butanol. But this value could be drastically reduced

2 (to about $20 \%$ or even less) when the distillation process is combined with in-situ product recovery (ISPR) techniques (Bildea et al., 2016; Xue et al., 2014).

This work proposes a novel downstream process using only several operating units in an optimized distillation sequence - including process intensification options such as dividingwall column technology, as well as heat integration - that can radically reduce the costs and improve the economics of biobutanol production. The study considers a process simulated and optimized using Aspen Plus, with a plant capacity of 40 ktpy butanol (Kraemer et al., 2011) and product purities of $99.4 \%$ wt butanol, $99.4 \%$ wt acetone and $91.4 \%$ wt ethanol.

\section{Problem statement}

The conventional butanol recovery by distillation is an energy-intensive process, which has largely restricted the economic production of biobutanol. However, other butanol recovery processes (e.g. gas stripping, extraction, adsorption, membrane-based) require about 5-7 operating units in total (leading to high capital cost) and an energy intensive operation due to the bulk removal of water from the diluted fermentation broth (Kiss et al., 2016).

Figure 1 illustrates some of the options described in literature (van der Merwe et al., 2013). The problem is that all these designs have some major drawbacks that hinder their implementation in practice. For example, in designs A, B and C, the ethanol column must achieve extremely high recovery of this component. Otherwise, because the butanol / water separation delivers the products as bottom streams of distillation columns, ethanol (the lightest component) will accumulate in the recycle streams. This has clearly a negative impact not only on the investment and operating costs, but also on the process controllability. Also, design D incurs additional costs due to use of a large amount of solvent for water recovery. To solve these downstream separation problems, we propose a novel distillation sequence able to reduce the costs of the downstream distillation of butanol. The improvements include:

- The column separating ethanol is part of the recycle loop of butanol-water separation, in order to prevent ethanol accumulation;

- The first unit of the sequence is a decanter, without pre-concentration steps, improving energy efficiency and preventing phase separation in the first distillation columns;

- Two distillation columns are replaced by a more efficient dividing-wall column;

- Heat-integration is used to minimize the energy requirements (Dimian et al., 2014). In addition, rigorous dynamic simulations (flow-driven and pressure-driven) are also used to prove the good controllability of the proposed integrated process. 


\section{3. Modeling approach}

3 The process was simulated in Aspen Plus using the NRTL property model that is most suitable for these components and process conditions and in line with the recommendations for such systems (Kiss, 2013). All the binary interaction parameters related to the property model are available in the pure components databank of the Aspen Plus process simulator (v8.4). Moreover, experimental composition of the binary system n-butanol / water obtained in the temperature range 323-393 $\mathrm{K}$ and pressures between 13.4 and $267 \mathrm{kPa}$ (Lee et al., 2004) was used to check that the butanol / water LLE is correctly predicted by the NRTL model with default Aspen Plus binary interaction parameters (Figure 2, left). Occurrence of a heterogeneous azeotrope (Figure 2, right) is a feature of the butanol-water mixture which is neatly exploited to cross the distillation boundary and therefore produce high purity products.

\subsection{Process selection}

Jin et al. (2011) described several integrated systems for ABE fermentation and in situ solvent recovery, where the fermentation process is coupled with e.g. gas stripping, liquid-liquid extraction (perstraction), and pervaporation. Among these options, gas stripping is a quite simple and inexpensive technique for recovering $\mathrm{ABE}$ from the fermentation broth. Nitrogen or fermentation gases $\left(\mathrm{CO}_{2}\right.$ and $\left.\mathrm{H}_{2}\right)$ are bubbled through the broth and capture the solvents (butanol or $\mathrm{ABE}$ ). Then the gas is passed through a condenser. The liquid solvents are collected, while the gas is recycled back to the fermenter to get more solvents. This cheap technique allows the collection of a more concentrated ABE mixture (4.5\%wt acetone, 18.6 $\%$ wt butanol, $0.9 \%$ wt ethanol) that is further treated by down-stream processing. The focus of this paper is on the efficient down-stream processing of the effluent stream from an $\mathrm{ABE}$ fermentation process coupled with gas stripping, as described in literature (Jin et al., 2011). There are different distillation sequences which can achieve the separation of the $\mathrm{ABE}$ mixture. Dimian et al. (2014) present heuristics aiming to minimize the capital and operating costs. For example, the designs A, B and C (Figure 1) suggested by van der Merwe et al. (2013) remove first the most plentiful component (water), followed by a direct separation sequence where light components (acetone and ethanol) are separated and leaving the most difficult split (n-butanol / water) at the end. Firstly, it should be noted that all these sequences will suffer from controllability problems: because ethanol has a lower boiling point, even tiny amounts of ethanol that enter the n-butanol / water separation sequence will be found in the distillate products; therefore, during operation, ethanol will accumulate in the recycle loops. 
1 Secondly, energy efficiency can be improved by rationalizing the use of a pre-fractionator.

Van der Merve et al. (2013) recommend the use of a pre-concentration step (beer stripper) removing water as bottoms and leaving the n-butanol / water azeotrope for further separation, similarly to the classic ethanol dehydration process. However, the fraction of n-butanol in the n-butanol / water azeotrope (42\%wt.) is much lower than the fraction of ethanol in the ethanol / water azeotrope (95\%wt.). Therefore, the use of a pre-concentration step is not fully justified in this case. Figure 3 presents the mass balance of two alternatives for separating a nbutanol - water mixture with a composition close to that found in the ABE process. A simplified mass balance reveals that the amount of top distillate products with azeotropic composition obtained with pre-concentration (Figure 3, case A: $0.6485 \mathrm{~kg}$ distillate per $\mathrm{kg}$ feed) is much higher than the amount distilled when the separation sequence starts with the liquid-liquid split (Figure 3, case B: $0.2717 \mathrm{~kg}$ distillate per $\mathrm{kg}$ feed).

\subsection{Process optimization}

After developing the base case, the new design was optimized using the total annual cost (TAC) as objective function to be minimized (Bildea et al., 2016):

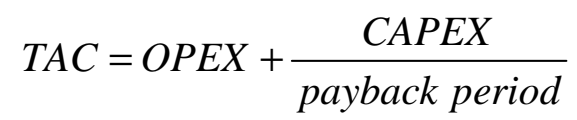

A payback period of 3 years and 8000 hours/year operating time was assumed. The capital cost was evaluated according to Dimian (2003). The heating and cooling costs taken into account are: LP steam (6 bar, $\left.160{ }^{\circ} \mathrm{C}, \$ 7.78 / \mathrm{GJ}\right)$, and cooling water $(\$ 0.72 / \mathrm{GJ})$. Note that the costs of utilities used here are typical for a US plant.

The total investment costs (CAPEX) include the heat exchangers, distillation columns, and decanter. The cost of the equipment can be estimated using standard cost correlations:

$$
C_{H E X}(U S \$)=(M \& S / 280) \cdot\left(474.7 \cdot A^{0.65}\right)\left(2.29+F_{m}\left(F_{d}+F_{p}\right)\right)
$$

where $M \& S$ is the Marshall \& Swift equipment cost index $(M \& S=1536.5$ in 2012), $A$ is the area $\left(\mathrm{m}^{2}\right), F_{m}=1$ (carbon steel), $F_{d}=0.8$ (fixed-tube), $F_{p}=0$ (less than 20 bar). A heat transfer coefficient $U=500 \mathrm{kcal} / \mathrm{m}^{2} / \mathrm{h} / \mathrm{K}$ was assumed to calculate the heat transfer area. For the reboilers, the design factor was taken as $F_{d}=1.35$.

The distillation columns diameter $(D)$ were obtained by the tray sizing utility from Aspen Plus, while the height was evaluated as $H=0.6 \cdot(N T-1)+2(\mathrm{~m})$. Afterwards, the cost of the columns shell was calculated as:

$C_{\text {shell }}(U S \$)=(M \& S / 280) \cdot\left(957.9 \cdot D^{1.066} \cdot H^{0.82}\right) \cdot\left(2.18+F_{c}\right)$ 
$1 \quad$ where $F_{\mathrm{c}}=F_{m} \cdot F_{p}, F_{m}=1$ (carbon steel) and $F_{p}=1+0.0074 \cdot(P-3.48)+0.00023 \cdot(P-3.48)^{2}$

2 The cost of the trays was given by:

$3 \quad C_{\text {trays }}(U S \$)=N_{T} \cdot(M \& S / 280) \cdot 97.2 \cdot D^{1.55} \cdot\left(F_{t}+F_{m}\right)$

4 with $F_{t}=0$ (sieve trays) and $F_{m}=1$ (carbon steel).

For each distillation column, the following optimization procedure was used:

- Choose the number of separation stages $(N T)$

- Implement two Aspen Plus design specification blocks which adjust the distillate to feed and reflux ratios in order to achieve specified product purities

- By sensitivity analysis, determine the feed tray that gives the minimum reboiler duty

- Calculate the Total Annual Cost (TAC)

- Change the number of separation stages $(N T)$ and repeat the previous steps until the column leading to minimum TAC is found.

Note that using a complete flowsheet optimization might lead to slightly improved process parameters and somewhat lower total annual costs. However, a global optimum design for the process can not be guaranteed, since this is typically a mixed-integer nonlinear problem (MINLP) that is non-convex and likely to have multiple locally optimal solutions. Such problems are intrinsically very difficult to solve, and the solution time increases rapidly with the number of variables and constraints. A theoretical guarantee of convergence to the globally optimal solution is not possible for non-convex problems (Luo et al., 2015).

\section{Results and discussion}

In this section, the results are provided for a plant capacity of $40 \mathrm{ktpy}$ butanol, processing an effluent stream from an $\mathrm{ABE}$ fermentation process coupled with gas stripping and delivering products with purities of $99.4 \%$ wt butanol, $99.4 \%$ wt acetone and $91.4 \%$ wt ethanol, thus meeting the standard ASTM D7862-13 specification of $>96 \%$ purity for use as blendstock.

\subsection{Base-case design}

Figure 4 presents the flowsheet of the new down-stream processing sequence for the $\mathrm{ABE}$ process, including the proposed control structure along with the mass balance and the key design parameters. The first unit of the sequence is a decanter. This minimizes the energy requirements as previously discussed and also prevents potential phase separations in the subsequent distillation columns. The organic phase (rich in butanol) goes to the first stripping column (COL-1) that separates butanol as bottom product and a water rich, top vapor stream 
1 which is recycled to the decanter by means of a blower. The aqueous phase from the decanter is fed to the stripping column (COL-2) that separates water as bottom product (main water outlet). The top stream of the stripping column (COL-2) is fed to the distillation column (COL-3) that separates an acetone-ethanol rich fraction (the amount of water roughly correspond to the ethanol/ water azeotrope) as top distillate stream and a butanol-water bottom stream that is recycled to the decanter. The acetone-ethanol stream from this column (COL-3) is sent to distillation column (COL-4) that separates ethanol and water as bottom product and acetone as top distillate. The column separating ethanol (COL-3), which is part of the recycle loop of the butanol-water separation, prevents ethanol accumulation although a high value for the ethanol recovery in the distillate is not required. Figure 5 shows the liquid composition profiles along the columns. Due to the high purity, quite a large number of trays are necessary for the columns delivering the butanol, acetone and ethanol products (COL-1 and COL-4). However, the splits (water, butanol) / (water) and (acetone, ethanol) / (water, butanol) are rather easy and can be achieved with a low number of trays (COL-2 and COL-3).

Table 1 conveniently summarizes the cost of equipment and utilities required for the base case process design, as well as the total annual cost. More details are provided in the subsequent section about the economic evaluation.

Furthermore, a dynamic simulation was built in Aspen Dynamics to check the controllability of the process. All vessels were sized based on 15 minutes residence time. The control structure involves simple controllers, chosen as PI and tuned by the direct-synthesis method. Figure 6 shows the results of the dynamic simulation, which starts from steady state. At time $t$ $=10 \mathrm{~h}$, the feed flow rate is increased by $10 \%$; then, at time $\mathrm{t}=20 \mathrm{~h}$, the feed flow rate returns to its original value; lastly at time $\mathrm{t}=30 \mathrm{~h}$, the feed flow rate is reduced by $10 \%$. Remarkable, all the disturbances are properly rejected, with low overshooting and short response times.

\subsection{Process intensification alternative}

Considering the indirect sequence of columns (COL-2 and COL-3) that operate at similar conditions, it is certainly worth considering the option of using a dividing-wall column (DWC) to replace these two distillation column (Yildirim et al., 2011; Kiss, 2013). The first step in designing a DWC is to check in a shortcut model how the separation influences the duty requirement and the column configuration. A DWC is thermodynamically equivalent to a Petlyuk distillation setup consisting of a prefractionator and a main column (Kiss, 2013). The prefractionator $(\mathrm{PF})$ and the main column are designed starting with a shortcut model to find the design parameters of the column (trays number, reflux ratio, duty requirements, liquid \& 
1 vapor split ratios) and after that using a rigorous RADFRAC model in Aspen Plus. The 2 following parameters are used for the minimization of the heat duty and total annual cost: number of stages in prefractionator and in the main column, feed stage location, position of the prefractionator in the main column, liquid and vapor split ratios. Varying the prefractionator feed stage, the lowest duty requirement is found when the prefractionator is fed on the 1st stage, and without any liquid coming from the main column. Figure 7 shows the liquid and vapor flow rates along the prefrationator and the main column of the DWC. The optimal design of the DWC was obtained for a configuration with 5 stages in the prefrationator and 23 stages in the main column, as clearly illustrated in Figure 8. It should be remarked that, irrespective of the number of stages in the prefractionator and main column, the optimum feed location is the top prefractionator stage. Moreover, lowest duty was found when there is no liquid flow from the main column to the prefractionator. During the optimization procedure, it was found that larger energy savings can be achieved by increasing the main column side draw. However, some hydraulic constraints must be fulfilled. The small liquid flow from the side-draw stage to the stage below should be noticed. This implies that the side-draw tray must be equipped with a different type of downcomer. Therefore, during the optimization procedure, the side-draw was limited such that at least 200 $\mathrm{kg} / \mathrm{h}$ of liquid flows to the tray below. This lead to a small penalty $(\sim 27-55 \mathrm{~kW})$ in terms of energy savings, compared to the unconstrained optimization.

For convenience, Figure 9 presents the updated flowsheet of the new downstream processing sequence using a DWC that replaces two distillation columns (COL-2 and COL-3) of the base case, including the control structure, heat integration, mass balance and the design parameters. Note that for each case of DWC design, an optimization of the total annual cost was made taking into account the other columns as well. Figure 10 illustrates the minimization process for all distillation columns. Moreover, (process-process / feed effluent) heat exchangers are used to pre-heat the feed to each distillation column in order to reduce the overall heat duties. Table 2 provides an overview of the optimization results. Replacing two distillation columns with a DWC unit leads to about $15 \%$ energy savings, while the heat integration manages to add another $10 \%$ savings, leading to an overall total of $25 \%$ energy savings as compared to the optimized base case scenario. Figure 11 shows the liquid composition profiles along the optimized distillation columns. The profiles in COL-1 and COL-4 are practically the same as in the base case (shown in Figure 5), but with an increased number of stages in COL-1 (from 36 to 39 stages), which can be explained by the amount of acetone and ethanol that is recycled back to the decanter unit. 


\section{$2 \quad 4.3$ Economic evaluation}

3 The equipment cost, utilities cost (proportional to the energy requirements per each unit) and the total annual costs are listed in Table 1 for the base case (TAC $=4214.5 \cdot 10^{3} \mathrm{US} \$ /$ year), and in Table 3 for the heat integrated process with DWC (TAC $=3390.5 \cdot 10^{3}$ US $\$ /$ year). Clearly, the heat integrated alternative with a DWC is a better option, allowing $20 \%$ savings. Note that the total equipment cost takes into account the decanter, all the distillation columns (including heat exchangers: reboilers and condensers), and the process-process heat exchangers, while the total operating costs include the heating and cooling utilities (low pressure steam, 6 bar, $160{ }^{\circ} \mathrm{C}, \$ 7.78 / \mathrm{GJ}$ and cooling water, $\left.\$ 0.72 / \mathrm{GJ}\right)$.

In terms of specific energy requirements, this is $2.28 \mathrm{kWh} / \mathrm{kg}$ butanol for the base case, while for the heat integrated DWC process it amounts $1.71 \mathrm{kWh} / \mathrm{kg}$ butanol (about $25 \%$ reduction). However, in the ABE process, each $\mathrm{kg}$ of butanol yields also $0.243 \mathrm{~kg}$ acetone (high purity) and $0.054 \mathrm{~kg}$ ethanol (near azeotropic composition with water) by-products which could be considered valuable and having a favorable contribution to the economics of the process. Furthermore, taking into account that the last distillation column (COL-4) is used only for the optional separation of the by-products (acetone and ethanol mixture), its duty should not be accounted for the specific energy requirements of butanol but for acetone and ethanol. In this case, only the heat duties of COL-1 and DWC contribute to the specific energy requirement of butanol, which reduces to $1.24 \mathrm{kWh} / \mathrm{kg}(4.46 \mathrm{MJ} / \mathrm{kg}$ ) butanol (about $45 \%$ reduction compared to the base case). To put these results into context, it should be remarked that the classic distillation-decanter method requires $4-22 \mathrm{kWh} / \mathrm{kg}(14.5-79.5 \mathrm{MJ} / \mathrm{kg})$ of butanol $99.5-99.9$ \%wt (Kujawska et al., 2015). Note that using heat pumps (such as vapor compression or vapor recompression) could further improve the efficiency of the distillation processes and reduce the primary energy use, but at the expense of higher CAPEX (Luo et al., 2015; Grisales Diaz and Olivar Tost, 2016; Kiss and Infante Ferreira, 2016). Also, novel dual extraction processes could get to rather low energy requirements, but at the cost of using additionally non-biocompatible solvents (Kurkijärvi et al., 2014).

\subsection{Dynamic simulations and process control}

The control of integrated and optimized processes plays an important role, since the process control ensures the high availability of the plant and thus guarantees that the actual energy savings of the optimal design are also achievable in practical operation. Dynamic simulations 
1 Figure 12 presents the results of the flow driven simulation. The controllability of the conventional vs DWC flowsheet are compared in Table 4, using the maximum error, the offset (steady-state error), and the integral of the absolute error (IAE) as criteria, for all products and different disturbances. Clearly, the controllability of the conventional flowsheet is only marginally better, compared to the more integrated DWC setup. The liquid levels in the decanter, reflux drums and column sumps are controlled by flow rates of the organic and aqueous phase, distillate and bottoms product, respectively. Feed with all recycles streams are cooled for decanting at the same temperature. In each column, pressure is controlled by condenser duty, while the reboiler duty is used to control temperature on a sensitive stage (stage 5 in COL-1, stage 26 in COL-4, stage 3 in PF part of the DWC). COL-4 is operated at constant reflux rate while in the DWC the reflux rate is used for temperature control (stage 5). The side stream flow rate of the DWC controls the butanol concentration in this side stream. In all cases, the simulation starts from steady state. At time $\mathrm{t}=2 \mathrm{~h}$, the feed flow rate is increased by $10 \%$, then at time $\mathrm{t}=12 \mathrm{~h}$, the feed flow rate returns to its initial value, and at time $\mathrm{t}=22 \mathrm{~h}$ the feed is reduced by $10 \%$. Remarkable, all the disturbances are properly rejected, with low overshooting and short response time.

Figure 13 and Figure 14 present results of pressure driven simulation, for changes in the feed flow rate (same scenario as described above) and composition (from the initial value 18.5 \%wt., the butanol mass fraction is increased, at time $t=2 \mathrm{~h}$, to $20.4 \% \mathrm{wt}$, while the mass fraction of the other components is decreased, proportionally to their concentration. At time $t$ $=22 \mathrm{~h}$, butanol mass fraction is decreased to $16.6 \% \mathrm{wt}$ ). The pressure driven simulation give a more realistic view of process dynamics and allows a more rigorous controllability analysis. In particular, the change of the liquid flows down the prefractionator and the DWC affect the height of liquid on each tray and therefore the resistance to the vapor flow. While the flow driven simulation assumes that the vapor split between the prefractionator and the main column is fixed, the pressure driven simulation correctly calculates the flows based on pressure difference and trays hydraulic resistance. However, pressure driven simulation is also more demanding, requiring correct sizing of all pumps and valves in the flowsheet. Table 5 lists the controller tuning parameters, while Table 6 provides the pumps and valves characteristics used in the dynamic simulations. The extremely good controllability of the DWC configuration is also confirmed, the product flow rates following the amounts of acetone, ethanol and butanol in the feed, with purities practically unchanged. 


\section{Conclusions}

The new downstream processing distillation sequence proposed in this work allows the efficient separation of butanol using fewer equipment units and less energy as compared to previously reported studies (e.g. Kraemer et al., 2011; van der Merwe et al., 2013; Errico et al., 2015). The main improvements include using a decanter as the first unit of the separation sequence avoiding the use of a pre-concentration step and preventing phase separation in the stripping and distillation columns, placing the column separating ethanol in the recycle loop of the butanol-water separation to prevent ethanol accumulation, using dividing-wall column as process intensification method of improvement, as well as employing heat integration. For a commercial plant capacity of $40 \mathrm{ktpy}$ butanol, the total equipment cost (including decanter, blower, all distillation columns and heat exchangers) is $4232 \cdot 10^{3}$ US\$, while the total energy costs are $2128 \cdot 10^{3}$ US\$/year. Remarkably, the specific energy requirements for the separation and purification of butanol is very low $(1.24 \mathrm{kWh} / \mathrm{kg}$ butanol), especially considering that butanol fuel has an energy density of about $10 \mathrm{kWh} / \mathrm{kg}(36 \mathrm{MJ} / \mathrm{kg})$. As this novel enhanced process uses only proven technology, it can be readily employed at large scale to improve the economics of the downstream processing in the ABE fermentation process.

\section{Acknowledgement}

Financial support of the European Commission through the European Regional Development Fund and of the Romanian state budget, under the grant agreement 155/25.11.2016 (Project POC P-37-449, acronym ASPiRE) is gratefully acknowledged.

\section{References}

1. Abdehagh N., Tezel F. H., Thibault J., Separation techniques in butanol production: Challenges and developments, Biomass and Bioenergy, 60 (2014), 222-246.

2. Bildea C. S., Patrascu I., Segovia-Hernandez J. G., Kiss A. A., Enhanced down-stream processing of biobutanol in the ABE fermentation process, Computer Aided Chemical Engineering, 38 (2016), 979-984.

3. Blahusiak M., Kiss A. A., Kersten S. R. A., Schuur B., Quick assessment of binary distillation efficiency using a heat engine perspective, Energy, 116 (2016), 20-31.

4. Dimian A. C., Integrated design and simulation of chemical processes, Elsevier, 2003.

5. Dimian A. C., Bildea C.S., Kiss A. A., Integrated design and simulation of chemical processes, 2nd edition, Elsevier, Amsterdam, 2014.

6. Errico M., Sanchez-Ramirez E., Quiroz-Ramìrez J. J., Segovia-Hernández J. G., Rong B. 
G., Alternative hybrid liquid-liquid and distillation sequences for the biobutanol separation, Computer Aided Chemical Engineering, 37 (2015), 1127-1132.

7. Green E. M., Fermentative production of butanol - The industrial perspective, Current Opinion in Biotechnology, 22 (2011), 337-343.

8. Grisales Diaz V. H., Olivar Tost G., Ethanol and isobutanol dehydration by heatintegrated distillation, Chemical Engineering and Processing, 108 (2016), 117-124.

9. Huang H. J., Ramaswamy S., Liu Y-Y., Separation and purification of biobutanol during bioconversion of biomass, Separation and Purification Technology, 132 (2014), 513-540.

10. Huang H. J., Ramaswamy S., Tschirner U. W., Ramarao B. V., A review of separation technologies in current and future biorefineries, Separation and Purification Technology 62 (2008), 1-21.

11. Jin C., Yao M., Liu H., Lee C. F., Ji J., Progress in the production and application of nbutanol as a biofuel, Renewable and Sustainable Energy Reviews, 15 (2011), 4080-4106.

12. Kiss A. A., Advanced distillation technologies - Design, control and applications. Wiley, Chichester, UK, 2013.

13. Kiss A. A., Novel applications of dividing-wall column technology to biofuel production processes, Journal of Chemical Technology and Biotechnology, 88 (2013), 1387-1404.

14. Kiss A. A., Distillation technology - Still young and full of breakthrough opportunities, Journal of Chemical Technology and Biotechnology, 89 (2014), 479-498.

15. Kiss A. A., Grievink J., Rito-Palomares M., A systems engineering perspective on process integration in industrial biotechnology, Journal of Chemical Technology and Biotechnology, 90 (2015), 349-355.

16. Kiss A. A., Infante Ferreira C. A., Heat pumps in chemical process industry, CRC-Press, Taylor \& Francis Group, 2016.

17. Kiss A. A., Lange J. P., Schuur B., Brilman D. W. F., van der Ham A. G. J., Kersten S. R. A., Separation technology - Making a difference in biorefineries, Biomass and Bioenergy, 95 (2016), 296-309.

18. Kraemer K., Harwardt A., Bronneberg R., Marquardt W., Separation of butanol from acetone-butanol-ethanol fermentation by a hybrid extraction-distillation process, Computers and Chemical Engineering, 35 (2011), 949-963.

19. Kujawska A., Kujawski J., Bryjak M., Kujawski W., ABE fermentation products recovery methods - A review, Renewable and Sustainable Energy Reviews, 48 (2015), 648-661.

20. Kujawski J., Rozicka A., Bryjak M., Kujawski W., Pervaporative removal of acetone, butanol and ethanol from binary and multicomponent aqueous mixtures, Separation and Purification Technology, 132 (2014), 422-429.

21. Kurkijärvi A., Lehtonen J., Linnekoski J, Novel dual extraction process for acetone- 
butanol-ethanol fermentation, Separation and Purification Technology, 124 (2014), 18-25.

22. Lee M-J., Tsai L-H., Hong G-B., Lin H-M., Multiphase equilibria for binary and ternary mixtures containing propionic acid, n-butanol, butyl propionate, and water, Fluid Phase Equilibria, 216 (2004), 219-228.

23. Liu F., Liu L., Feng X., Separation of acetone-butanol-ethanol (ABE) from dilute aqueous solutions by pervaporation, Separation and Purification Technology, 42 (2005), 273-282.

24. Luo H., Bildea C. S., Kiss A. A., Novel heat-pump-assisted extractive distillation for bioethanol purification, Industrial \& Engineering Chemistry Research, 54 (2015), 2208-2213.

25. Mayank R., Ranjan A., Moholkar V.S., Mathematical models of ABE fermentation: Review and analysis, Critical Reviews in Biotechnology, 33 (2013), 419-447.

26. Tashiro Y., Yoshida T., Noguchi T., Sonomoto K., Recent advances and future prospects for increased butanol production by acetone-butanol-ethanol fermentation, Engineering in Life Sciences, 13 (2013), 432-445.

27. Van der Merwe A. B., Cheng H., Görgens J. F., Knoetze J. H., Comparison of energy efficiency and economics of process designs for biobutanol production from sugarcane molasses, Fuel, 105 (2013), 451-458.

28. Vane L. M., Separation technologies for the recovery and dehydration of alcohols from fermentation broths, Biofuels, Bioproducts and Biorefining, 2 (2008), 553-588.

29. Xue C., Zhao J-B., Liu F-F., Lu C-G., Yang S-T., Bai F-W., Two-stage in situ gas stripping for enhanced butanol fermentation and energy-saving product recovery, Bioresource Technology, 135 (2013), 396-402.

30. Xue C., Zhao J-B., Chen L-J., Bai F-W., Yang S-T., Sun J-X., Integrated butanol recovery for an advanced biofuel: Current state and prospects, Applied Microbiology and Biotechnology, 98 (2014), 3463-3474.

31. Xue C., Zhao X-Q., Lu C-G., Chen L-J., Bai F-W., Prospective and development of butanol as an advanced biofuel, Biotechnology Advances, 31 (2013), 1575-1584.

32. Yildirim O., Kiss A. A., Kenig E. Y., Dividing-wall columns in chemical process industry: A review on current activities, Separation and Purification Technology, 80 (2011), 403-417. 


\section{Tables}

3

4 Table 1. Economic evaluation of the base-case ABE downstream processing

\begin{tabular}{|c|c|c|c|c|c|c|}
\hline Item description (unit) & COL - 1 & COL - 2 & COL - 3 & COL - 4 & Decanter & Total \\
\hline Shell / [10 US\$] & 292.7 & 107.49 & 250.31 & 267.9 & 71.22 & 989.62 \\
\hline Trays / [10 US $\$]$ & 28.69 & 6.51 & 23.05 & 25.47 & - & 83.72 \\
\hline Condenser / $\left[10^{3}\right.$ US\$ $]$ & - & - & 557.02 & 560.75 & 303.9 & 1421.67 \\
\hline Reboiler / [10 US\$] & 567.05 & 788.19 & 245.62 & 325.33 & - & 1926.19 \\
\hline Heating / [10 $30^{3}$ US\$/year $]$ & 566.29 & 1223.24 & 224.47 & 539.81 & - & 2553.81 \\
\hline Cooling / [10³ US\$/year] & - & - & 77.06 & 50.18 & 11.52 & 138.76 \\
\hline TAC / [10 US $\$$ /year $] *$ & 862.46 & 1523.98 & 660.21 & 983.16 & 136.56 & 4214.59 \\
\hline
\end{tabular}

* Note: Total TAC includes CAPEX $\left(4.99 \cdot 10^{3}\right.$ US\$) and OPEX $\left(43.23 \cdot 10^{3}\right.$ US\$/year) of the blower recycling the top vapor stream of COL-1

7

8

9

10

11

12

13

14 15

Table 2. Energy usage in various scenarios: conventional, with DWC, and heat integrated process with DWC

\begin{tabular}{|c|c|c|c|c|c|c|c|}
\hline \multicolumn{6}{|c|}{ Energy Minimization Balance } & Total & Savings \\
\hline \multirow{2}{*}{ Conv. } & Unit & COL-1* & COL-2 & COL-3 & COL-4 & & \\
\hline & Duty $[\mathrm{kW}]$ & 2557.43 & 5459.35 & 1001.8 & 2409.21 & 11428 & $0 \%$ \\
\hline \multirow{2}{*}{ DWC } & Unit & COL-1 & \multicolumn{2}{|c|}{ DWC } & COL-4 & & \\
\hline & Duty $[\mathrm{kW}]$ & 2665.08 & \multicolumn{2}{|c|}{4725.74} & 2421.26 & 9812 & $-14.13 \%$ \\
\hline \multirow{2}{*}{$\begin{array}{l}\text { DWC } \\
\text { HeatInt }\end{array}$} & Unit & COL-1 & \multicolumn{2}{|c|}{ DWC } & COL-4 & & \\
\hline & Duty $[\mathrm{kW}]$ & 2497.42 & \multicolumn{2}{|c|}{3788.32} & 2350.04 & 8635 & $-24.43 \%$ \\
\hline
\end{tabular}


2 Table 3. Economic evaluation of the enhanced ABE down-stream separation heat integrated process with DWC

\begin{tabular}{|c|c|c|c|c|c|}
\hline Item description (unit) & COL - 1 & DWC & COL -4 & Decanter & Total \\
\hline Shell / [10 ${ }^{3}$ US\$] & 299.41 & 201.27 & 268.55 & 73.28 & 842.51 \\
\hline Trays / [10 US\$] & 29.54 & 17.28 & 25.55 & - & 72.37 \\
\hline Condenser / [10 $30^{3}$ US $\left.\$\right]$ & - & 553.56 & 562.23 & 777.94 & 1893.73 \\
\hline Reboiler / [10 $\left.30^{3} \mathrm{US} \$\right]$ & 561.34 & 537.40 & 320.12 & - & 1418.86 \\
\hline $\begin{array}{l}\text { Process-process heat } \\
\text { exchangers }\left[10^{3} \mathrm{US} \$\right]\end{array}$ & - & - & - & - & 163.38 \\
\hline Heating / [10 $30^{3}$ US\$/year $]$ & 550.25 & 848.82 & 526.56 & - & 1925.63 \\
\hline Cooling / [10 $30^{3}$ US $\$ /$ year $]$ & - & 53.09 & 50.38 & 48.93 & 152.4 \\
\hline $\mathrm{TAC} /\left[10^{3} \mathrm{US} \$ /\right.$ year $] *$ & 747.02 & 1232.02 & 969.10 & 332.67 & 3390.54 \\
\hline
\end{tabular}

Table 4. Comparison of control performance indexes for conventional and heat-integrated DWC for ABE downstream processing (flow-driven simulation).

\begin{tabular}{|c|c|c|c|c|c|c|c|}
\hline \multirow[t]{2}{*}{ Disturbance } & \multirow[t]{2}{*}{ Component } & \multicolumn{2}{|c|}{ Max error / [\%wt $]$} & \multicolumn{2}{|c|}{ Offset / [\%wt] } & \multicolumn{2}{|c|}{ IAE (over10h) / [\%wt·h] } \\
\hline & & CONV & DWC & CONV & DWC & CONV & DWC \\
\hline \multirow{4}{*}{$+10 \%$ feed } & acetone & 0.016 & 0.017 & 0.013 & 0.014 & 0.123 & 0.138 \\
\hline & ethanol & 0.031 & 0.136 & 0.021 & 0.137 & 0.241 & 0.438 \\
\hline & butanol & 0.020 & 0.028 & 0.015 & 0.023 & 0.161 & 0.234 \\
\hline & water & 0.172 & 0.112 & 0.059 & 0.005 & 0.658 & 0.180 \\
\hline \multirow{4}{*}{$-10 \%$ feed } & acetone & 0.0156 & 0.017 & 0.016 & 0.017 & 0.138 & 0.158 \\
\hline & ethanol & 0.0417 & 0.313 & 0.027 & 0.185 & 0.322 & 2.795 \\
\hline & butanol & 0.0208 & 0.024 & 0.018 & 0.020 & 0.176 & 0.208 \\
\hline & water & 0.0402 & 0.014 & 0.018 & 0.0003 & 0.343 & 0.022 \\
\hline
\end{tabular}


2 Table 5. Controller tuning parameters (pressure driven simulation)

\begin{tabular}{|c|c|c|c|c|}
\hline Controller & $P V$, value \& range & OP, value \& range & Kc, $\% / \%$ & Ti, min \\
\hline \multicolumn{5}{|l|}{ FEED } \\
\hline \multirow[t]{2}{*}{ FC } & Flow rate $=26945 \mathrm{~kg} / \mathrm{h}$ & valve opening $=50 \%$ & 1 & 1 \\
\hline & $0 \ldots 53921 \mathrm{~kg} / \mathrm{h}$ & $0 \ldots 100 \%$ & & \\
\hline \multicolumn{5}{|l|}{ COOLER } \\
\hline \multirow[t]{2}{*}{ TC } & Temperature $=40^{\circ} \mathrm{C}$ & duty $=-8.83 \mathrm{GJ} / \mathrm{h}$ & 1 & 20 \\
\hline & $37 \ldots 43{ }^{\circ} \mathrm{C}$ & $-17.42 \ldots 0 \mathrm{GJ} / \mathrm{h}$ & & \\
\hline \multicolumn{5}{|l|}{ DECANTER } \\
\hline \multirow[t]{2}{*}{$\mathbf{L C}$} & Liquid 1 Level $=2.38 \mathrm{~m}$ & valve opening $=50 \%$ & 1 & 20 \\
\hline & $0 \ldots 4.7 \mathrm{~m}$ & $0 \ldots 100 \%$ & & \\
\hline \multirow[t]{2}{*}{$\mathbf{L C}$} & Liquid 2 Level $=1.08 \mathrm{~m}$ & valve opening $=50 \%$ & 1 & 20 \\
\hline & $0 \ldots 2.17 \mathrm{~m}$ & $0 \ldots 100 \%$ & & \\
\hline \multicolumn{5}{|l|}{ COL - 1} \\
\hline \multirow[t]{2}{*}{$\mathbf{L C}$} & Sump level $=1.49 \mathrm{~m}$ & valve opening $=50 \%$ & 1 & 20 \\
\hline & $0 \ldots 2.99 \mathrm{~m}$ & $0 \ldots 100 \%$ & & \\
\hline \multirow[t]{2}{*}{ TC } & Stage 5 temperature $=114.1^{\circ} \mathrm{C}$ & reboiler duty $=9.08 \mathrm{GJ} / \mathrm{h}$ & 10 & 20 \\
\hline & $100 \ldots 125^{\circ} \mathrm{C}$ & $0 \ldots 18.01 \mathrm{~kg} / \mathrm{h}$ & & \\
\hline \multicolumn{5}{|l|}{ DWC } \\
\hline \multirow[t]{2}{*}{ PC } & Pressure $=1$ bar & condenser duty $=-10.15 \mathrm{GJ} / \mathrm{h}$ & 20 & 12 \\
\hline & $0 \ldots 2$ bar & $-18.51 \ldots 0 \mathrm{GJ} / \mathrm{h}$ & & \\
\hline \multirow[t]{2}{*}{$\mathbf{L C}$} & Reflux drum level $=1.76 \mathrm{~m}$ & valve opening $=50 \%$ & 1 & 20 \\
\hline & $0 \ldots 3.52 \mathrm{~m}$ & $0 \ldots 100 \%$ & & \\
\hline \multirow[t]{2}{*}{ LC } & Sump level =3.28 m & valve opening $=50 \%$ & 1 & 20 \\
\hline & $0 \ldots 6.5 \mathrm{~m}$ & $0 \ldots 100 \%$ & & \\
\hline \multirow[t]{2}{*}{ TC } & Stage 2 temperature $=60.29^{\circ} \mathrm{C}$ & reflux $=15272 \mathrm{~kg} / \mathrm{h}$ & 10 & 20 \\
\hline & $50 \ldots 70^{\circ} \mathrm{C}$ & $0 \ldots 30544 \mathrm{~kg} / \mathrm{h}$ & & \\
\hline \multirow[t]{2}{*}{ FC } & Side stream $=5649.77$ & valve opening $=50 \%$ & 20 & 10 \\
\hline & $0 \ldots 11299$ & $0 \ldots 100 \%$ & & \\
\hline \multicolumn{5}{|l|}{$\mathbf{P F}$} \\
\hline \multirow[t]{2}{*}{ TC } & Stage 5 temperature $=102.3^{\circ} \mathrm{C}$ & DWC reboiler duty $=14.40 \mathrm{GJ} / \mathrm{h}$ & 10 & 20 \\
\hline & $90 \ldots 113^{\circ} \mathrm{C}$ & $0 \ldots 27.21 \mathrm{GJ} / \mathrm{h}$ & & \\
\hline \multirow[t]{2}{*}{$\mathbf{L C}$} & Sump level $=0.18 \mathrm{~m}$ & valve opening $=49.5 \%$ & 1 & 20 \\
\hline & $0 \ldots 0.36 \mathrm{~m}$ & $0 \ldots 100 \%$ & & \\
\hline \multicolumn{5}{|l|}{ COL - 4} \\
\hline \multirow[t]{2}{*}{ PC } & Pressure $=1$ bar & condenser duty $=-8.77 \mathrm{GJ} / \mathrm{h}$ & 20 & 12 \\
\hline & $0 \ldots 2$ bar & $-17.56 \ldots 0 \mathrm{GJ} / \mathrm{h}$ & & \\
\hline \multirow[t]{2}{*}{$\mathbf{L C}$} & reflux drum level $=1.65 \mathrm{~m}$ & valve opening $=50 \%$ & 1 & 20 \\
\hline & $0 \ldots 3.30 \mathrm{~m}$ & $0 \ldots 100 \%$ & & \\
\hline \multirow[t]{2}{*}{$\mathbf{L C}$} & Sump level =1.4 m & valve opening $=50 \%$ & 1 & 20 \\
\hline & $0 \ldots 2.8 \mathrm{~m}$ & $0 \ldots 100 \%$ & & \\
\hline \multirow[t]{2}{*}{ TC } & Stage 26 temperature $=80^{\circ} \mathrm{C}$ & reboiler duty $=8.48 \mathrm{GJ} / \mathrm{h}$ & 1 & 10 \\
\hline & $70 \ldots 90^{\circ} \mathrm{C}$ & $0 \ldots 16.97 \mathrm{GJ} / \mathrm{h}$ & & \\
\hline
\end{tabular}


2 Table 6. Pumps and valves characteristics (pressure driven simulation)

3

\begin{tabular}{|c|c|c|c|c|c|c|c|c|c|}
\hline \multicolumn{3}{|c|}{ Pressure change devices } & \multicolumn{2}{|c|}{ Pump } & \multirow{3}{*}{$\begin{array}{c}\text { BPower } \\
{[\mathrm{kW}]}\end{array}$} & \multirow{3}{*}{$\begin{array}{c}\Delta P \\
{[\text { bar] }}\end{array}$} & \multicolumn{3}{|c|}{ Valve } \\
\hline & & & $F_{\max }$ & $H_{\max }$ & & & & $C_{0, \max }$ & $\Delta P$ \\
\hline & & & {$\left[\mathrm{m}^{3} / \mathrm{h}\right]$} & {$[\mathrm{m}]$} & & & & {$\left[\mathrm{m}^{1.5} \mathrm{~kg}^{0.5} / \mathrm{h} \cdot \mathrm{bar}^{0.5}\right]$} & bar \\
\hline \multirow{2}{*}{ COOLER } & FEED & $\mathrm{P} 1$ & 28.45 & 64.61 & 8.40 & 6.00 & V1 & 1012.08 & 5.99 \\
\hline & RECYCLE - 2 & $\mathrm{P} 7$ & 6.95 & 69.99 & 3.06 & 5.71 & V7 & 300.00 & 5.87 \\
\hline \multirow{2}{*}{ DECANTER } & ORGANIC & $\mathrm{P} 2$ & 12.90 & 48.21 & 3.12 & 4.00 & V2 & 531.65 & 3.99 \\
\hline & AQUEOUS & P4 & 29.09 & 43.05 & 5.70 & 4.00 & V4 & 1291.13 & 3.85 \\
\hline \multirow{2}{*}{ COL - 1} & FEED & $\mathrm{P} 2$ & 12.72 & 36.18 & 2.32 & 3.00 & V2 & 523.78 & 4.00 \\
\hline & вотTОМ & P3 & 7.15 & 81.48 & 3.02 & 5.60 & V3 & 218.89 & 6.00 \\
\hline \multirow{2}{*}{$\mathrm{PF}$} & FEED-LIQID & P4 & 29.24 & 32.14 & 4.28 & 2.98 & V4 & 1462.67 & 2.98 \\
\hline & ВоттОМ & P5 & 29.63 & 42.86 & 5.52 & 3.82 & V5 & 1294.48 & 3.81 \\
\hline \multirow[t]{5}{*}{ DWC } & DISTILLATE & P6 & 1.97 & 89.65 & 1.11 & 6.00 & V6 & 64.09 & 5.75 \\
\hline & SIDE STREAM & P7 & 6.79 & 71.55 & 3.04 & 5.83 & V7 & 229.96 & 5.87 \\
\hline & вотТОМ & P8 & 22.40 & 64.55 & 6.73 & 5.77 & V8 & 781.24 & 6.00 \\
\hline & FEED LIQUID & P5 & 29.76 & 42.69 & 5.53 & 3.80 & V5 & 1294.58 & 3.80 \\
\hline & FEED & P6 & 1.67 & 89.65 & 1.06 & 6.61 & V6 & 64.14 & 6.37 \\
\hline \multirow[t]{2}{*}{ COL - 4} & DISTILLATE & P9 & 1.62 & 81.35 & 0.91 & 6.00 & V9 & 51.53 & 6.62 \\
\hline & воттОМ & $\mathrm{P} 10$ & 0.36 & 78.50 & 0.19 & 5.70 & V10 & 11.33 & 6.00 \\
\hline
\end{tabular}

4

5

6 
$1 \quad$ Figure captions (auto-updated)

2

3 Figure 1. Flow diagrams for downstream processing of biobutanol in the ABE process (van 4 der Merwe et al., 2013)

5

Figure 2. Phase equilibrium of mixture butanol-water. Left: Comparison between LLE predicted by NRTL model (line) and experimental data (dots; Lee et al., 2004); Right: T-xy diagram, showing the occurrence of a heterogeneous azeotrope (1 bar).

Figure 3. Simplified alternatives for separation of a Butanol (20\%wt) - Water (80\%wt) mixture, with feed pre-concentration (Case A: $0.6485 \mathrm{~kg}$ total distillate $/ \mathrm{kg}$ feed) and without feed pre-concentration (Case B: $0.2717 \mathrm{~kg}$ total distillate / $\mathrm{kg}$ feed)

Figure 4. Process flowsheet of the new down-stream separation sequence (40 ktpy butanol)

Figure 5. Mass composition profiles in the stripping and distillation columns

Figure 6. Dynamic simulations results for the base-case: flow rates (left) and composition (right)

Figure 8. Energy optimization of the DWC configuration

Figure 9. Flowsheet of the process intensification alternative (using DWC) for the ABE

Figure 10. Total annual cost (TAC) optimization for the distillation columns

Figure 11. Mass composition profiles in the stripping, distillation columns and DWC

Figure 12. Dynamic simulations results (flow driven): flow rates (left) and composition (right)

Figure 13. Dynamic simulations results (pressure driven) - feed flow rate disturbance

Figure 14. Dynamic simulations results (pressure driven) - butanol concentration disturbance 35 

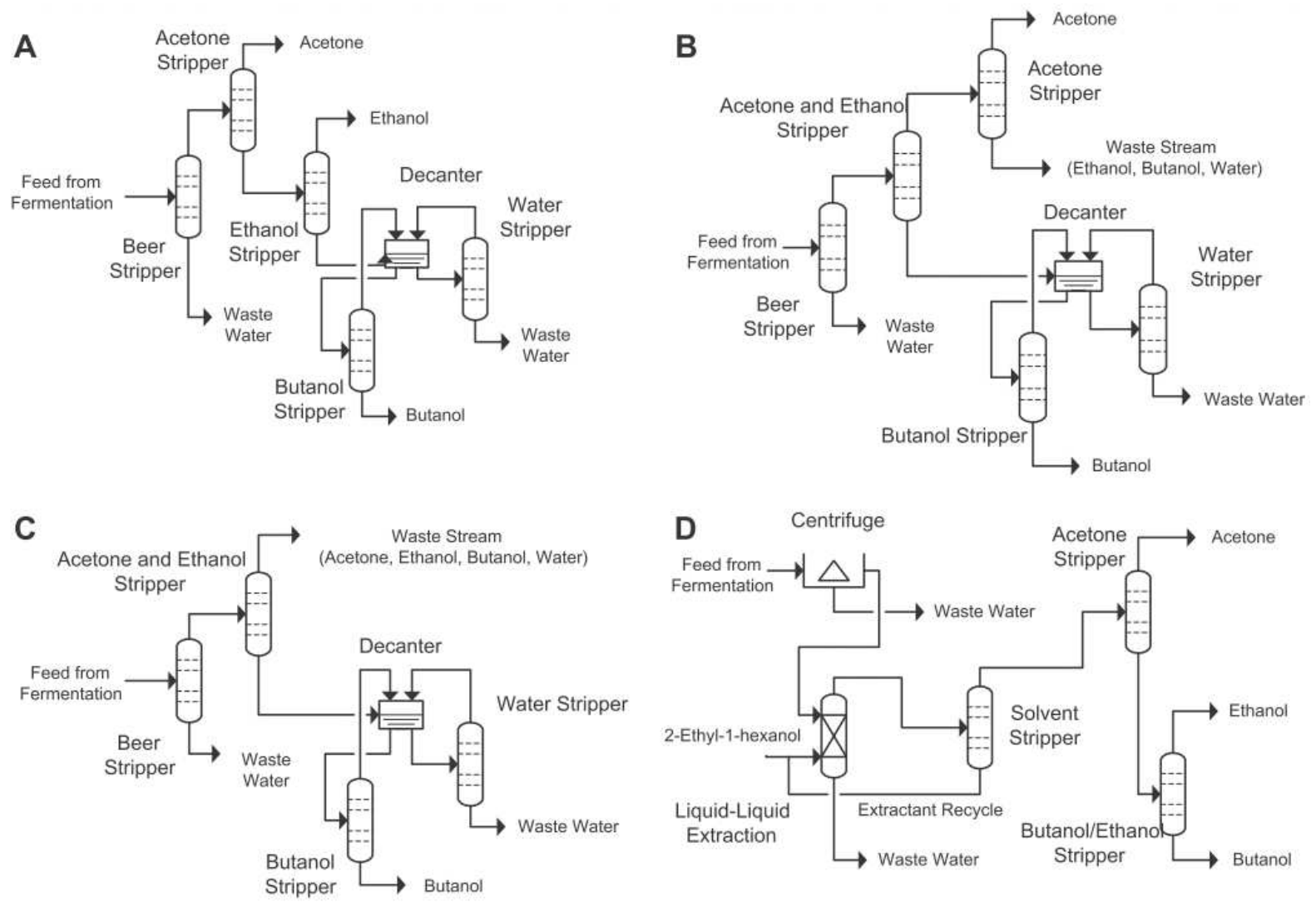

Figure 1. Flow diagrams for downstream processing of biobutanol in the ABE process (van
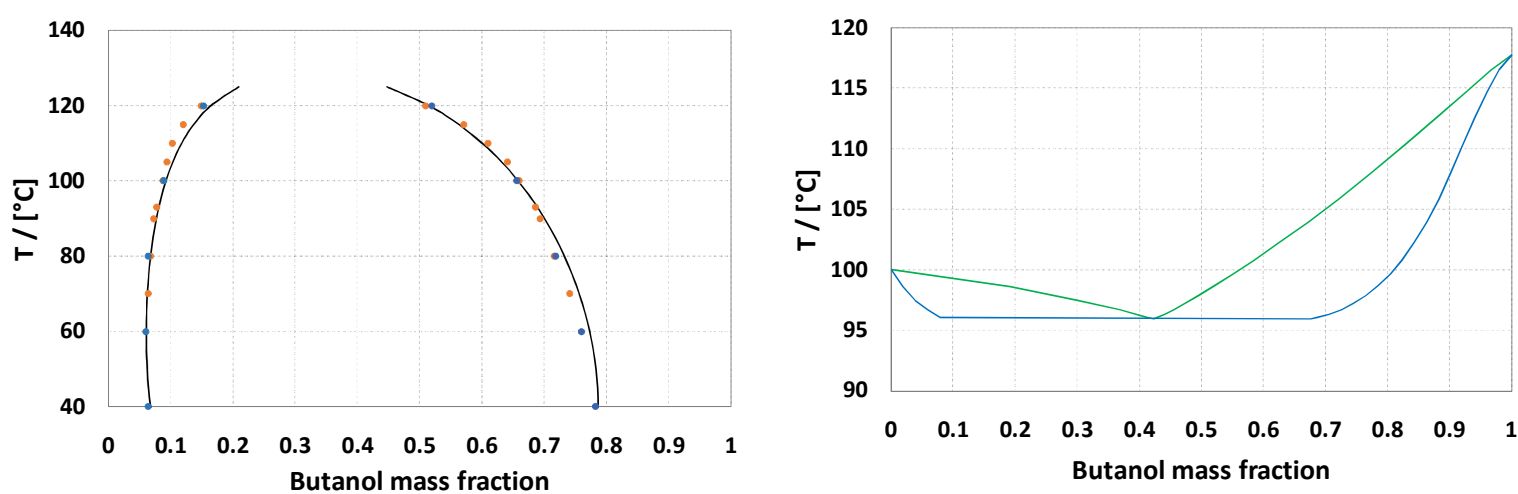

Figure 2. Phase equilibrium of mixture butanol-water. Left: Comparison between LLE predicted by NRTL model (line) and experimental data (dots; Lee et al., 2004); Right: T-xy diagram, showing the occurrence of a heterogeneous azeotrope (1 bar). 


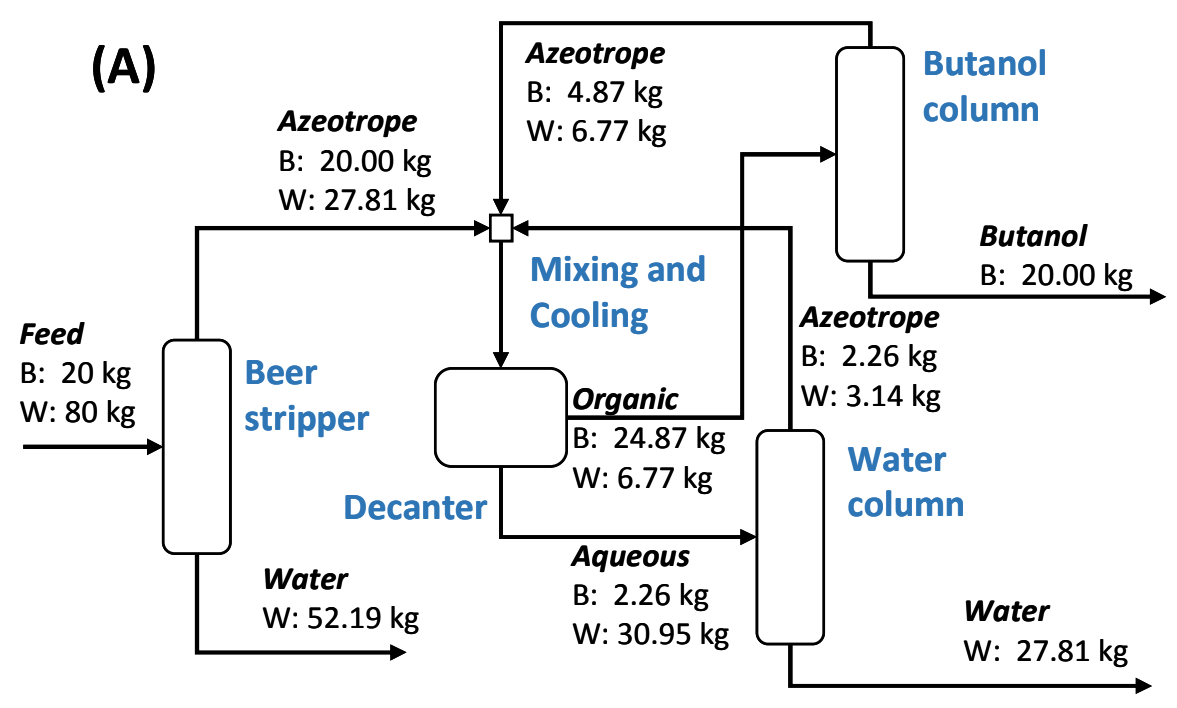

3

(B)

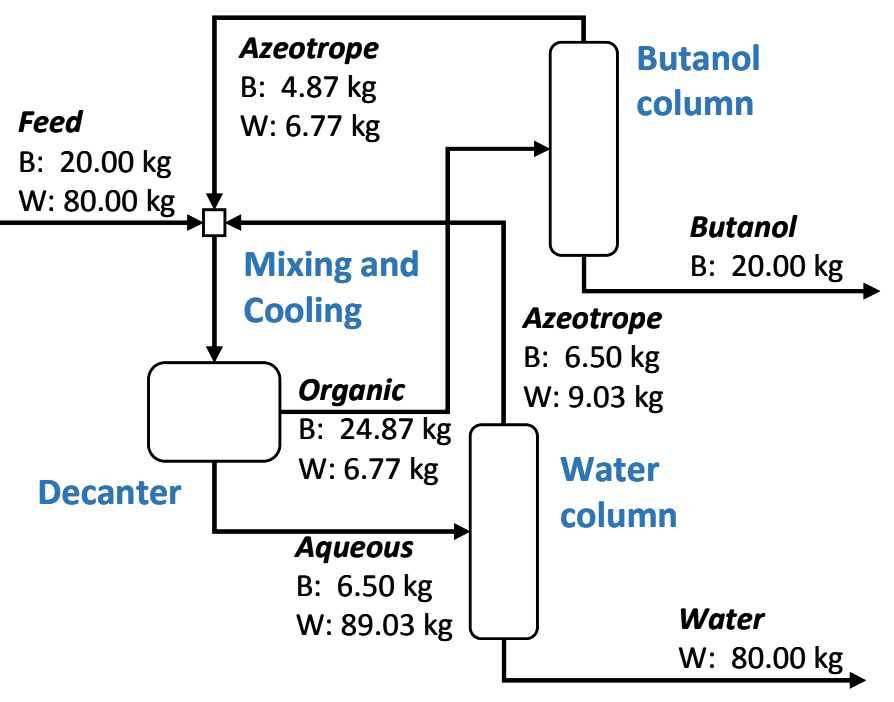

Figure 3. Simplified alternatives for separation of a Butanol $(20 \% \mathrm{wt})$ - Water $(80 \% \mathrm{wt})$ mixture, with feed pre-concentration (Case A: $0.6485 \mathrm{~kg}$ total distillate / $\mathrm{kg}$ feed) and without feed pre-concentration (Case B: $0.2717 \mathrm{~kg}$ total distillate / $\mathrm{kg}$ feed)

(1) (1) 1 

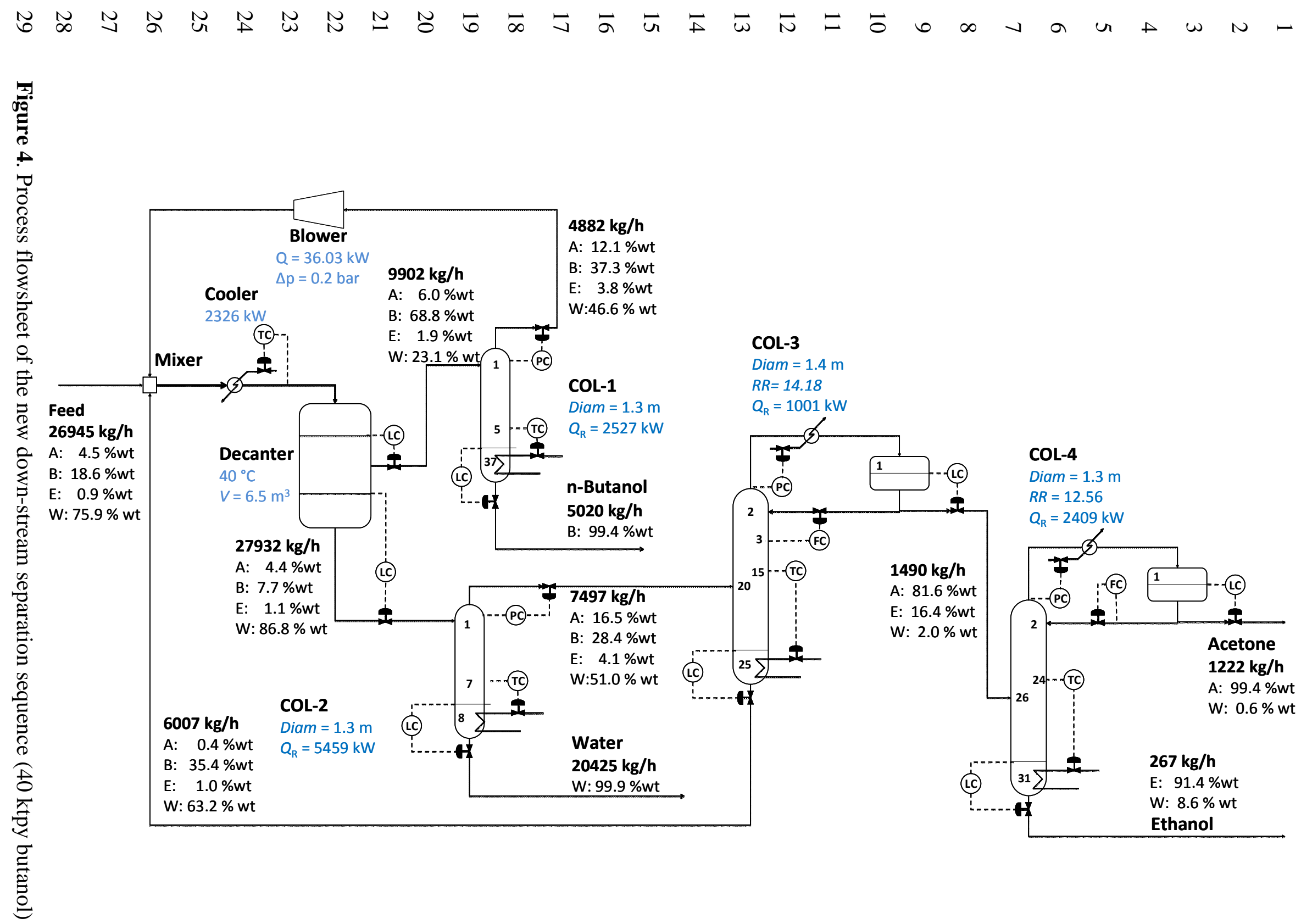

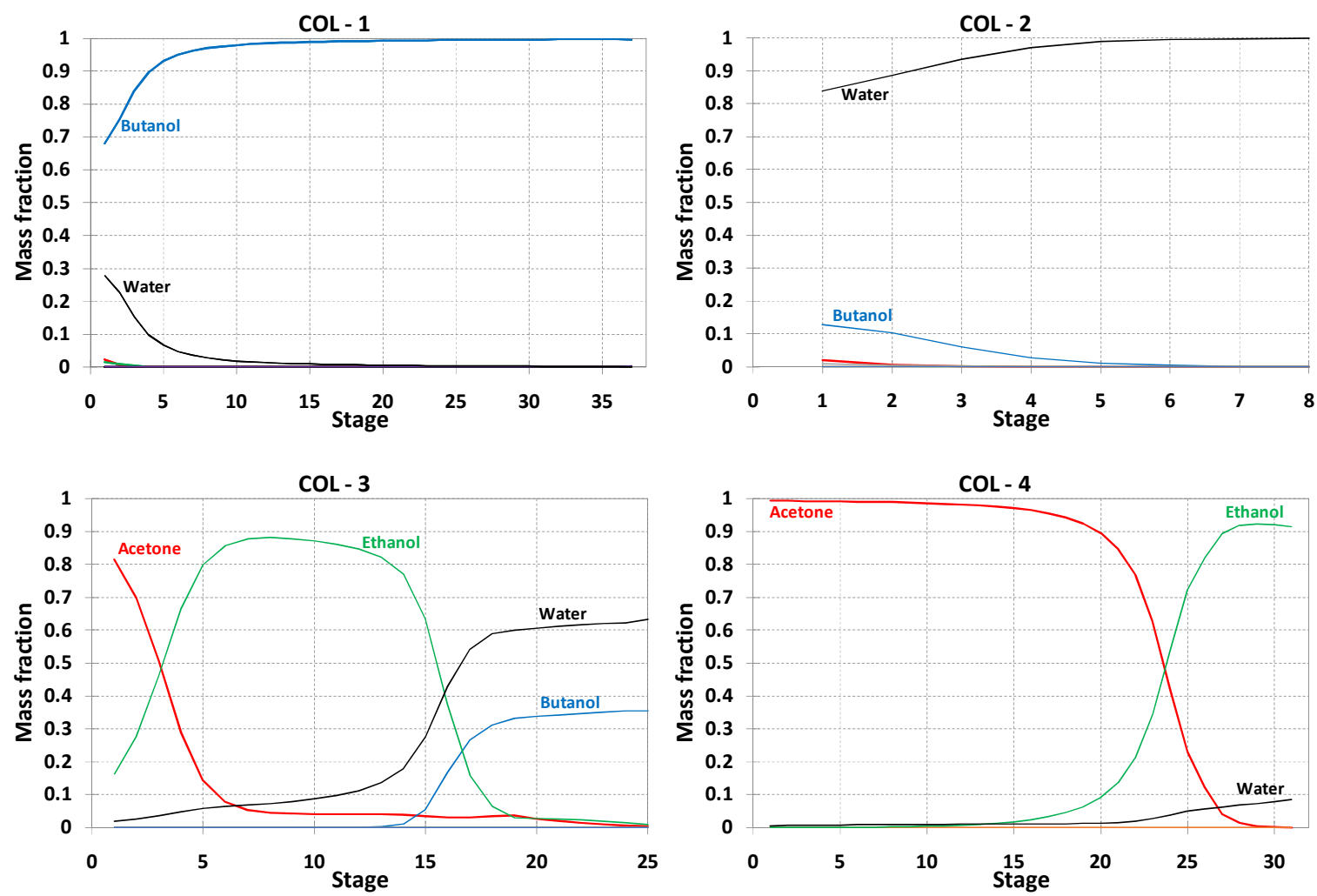

Figure 5. Mass composition profiles in the stripping and distillation columns
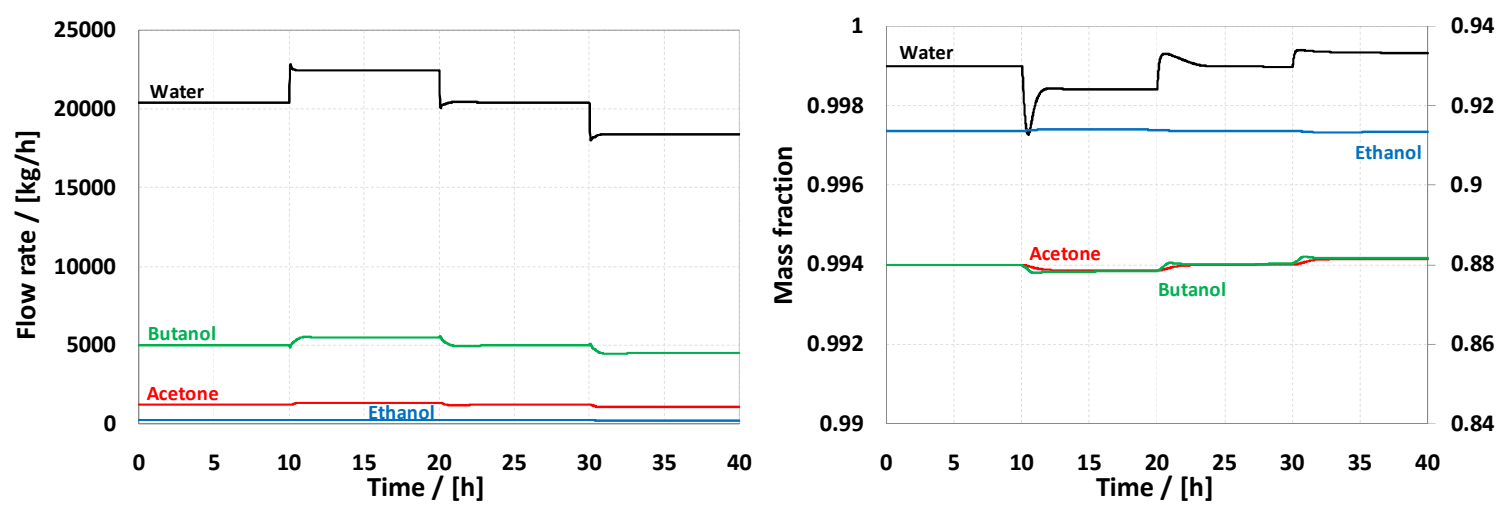

Figure 6. Dynamic simulations results for the base-case: flow rates (left) and composition 


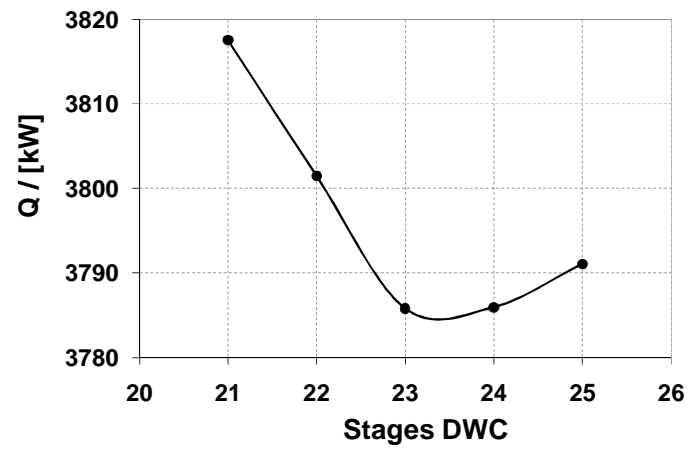

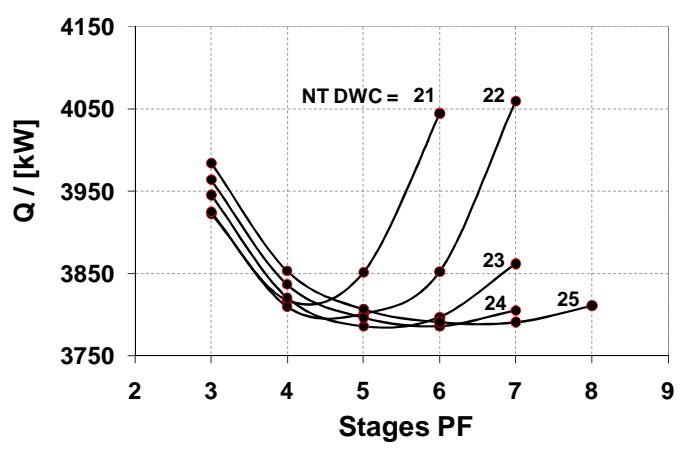

Figure 8. Energy optimization of the DWC configuration 


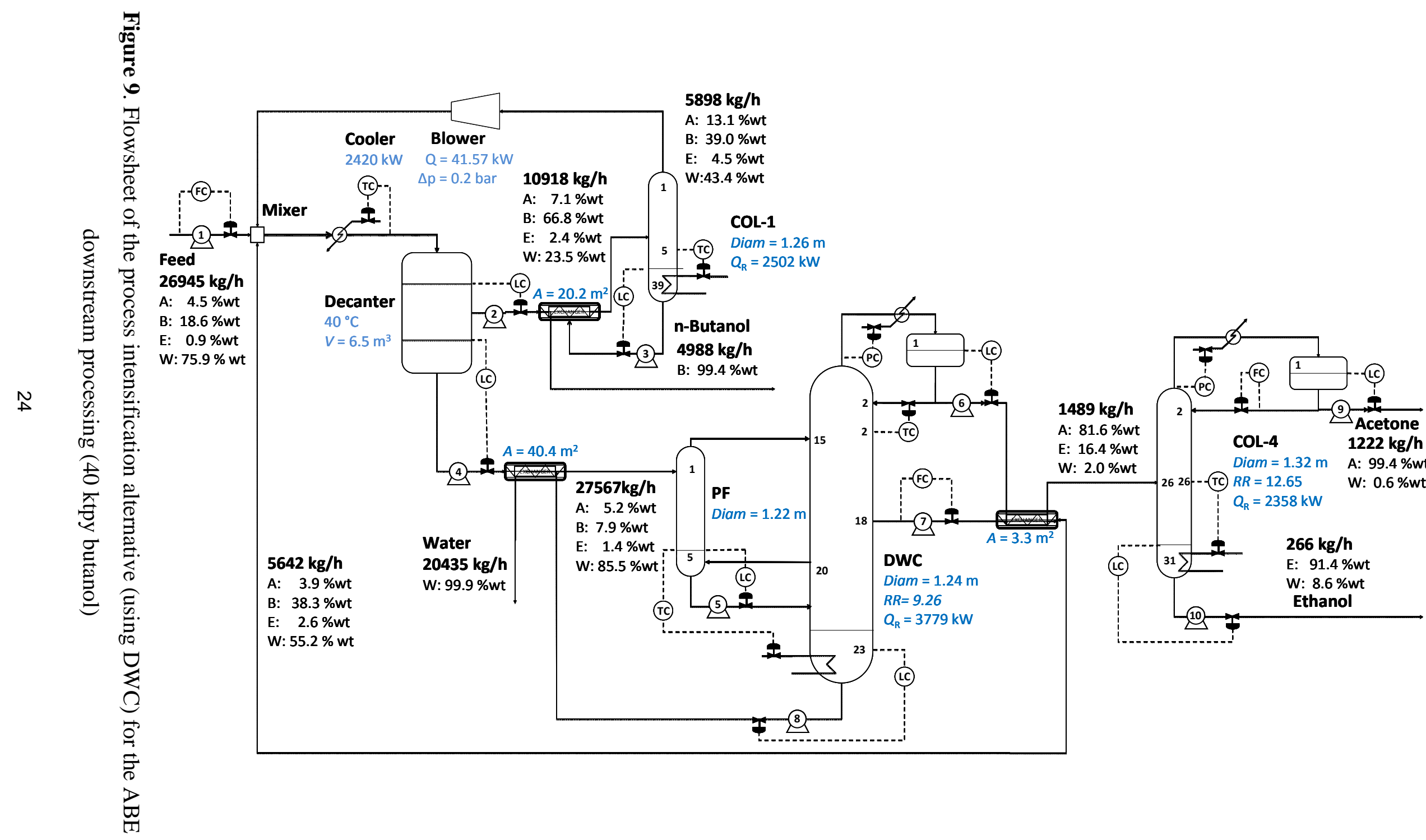




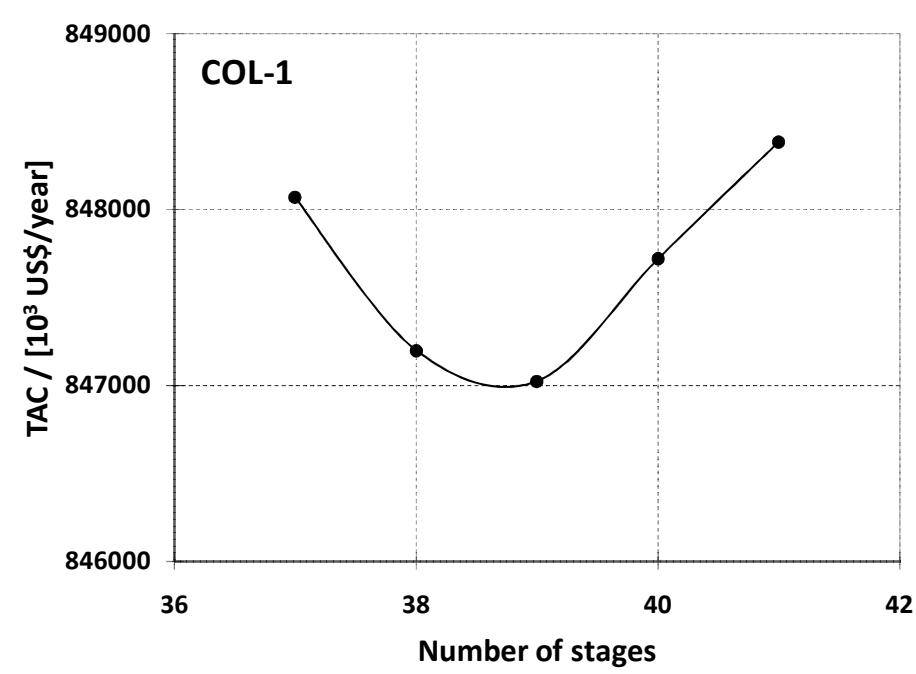

3

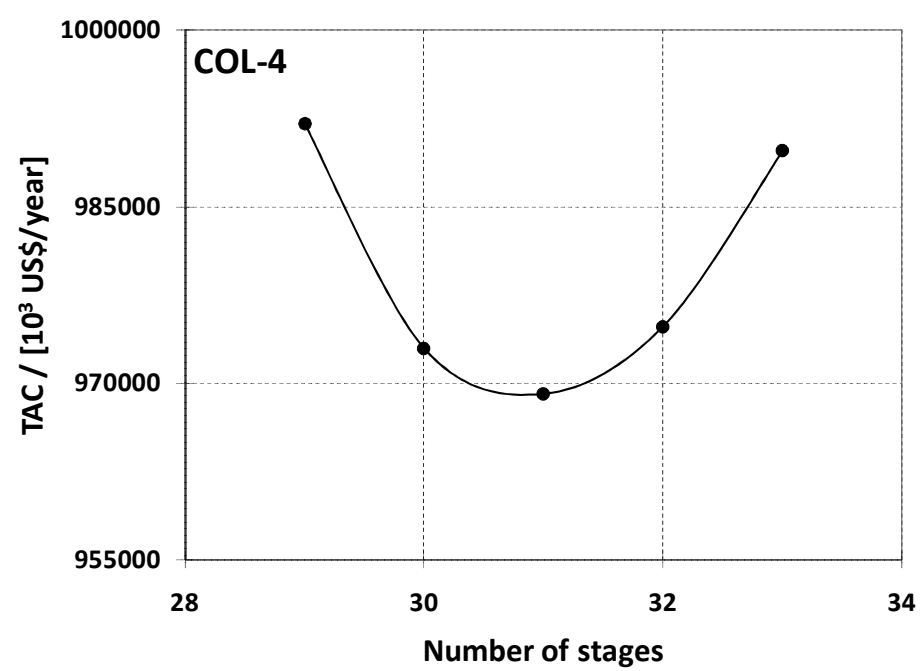

4

5

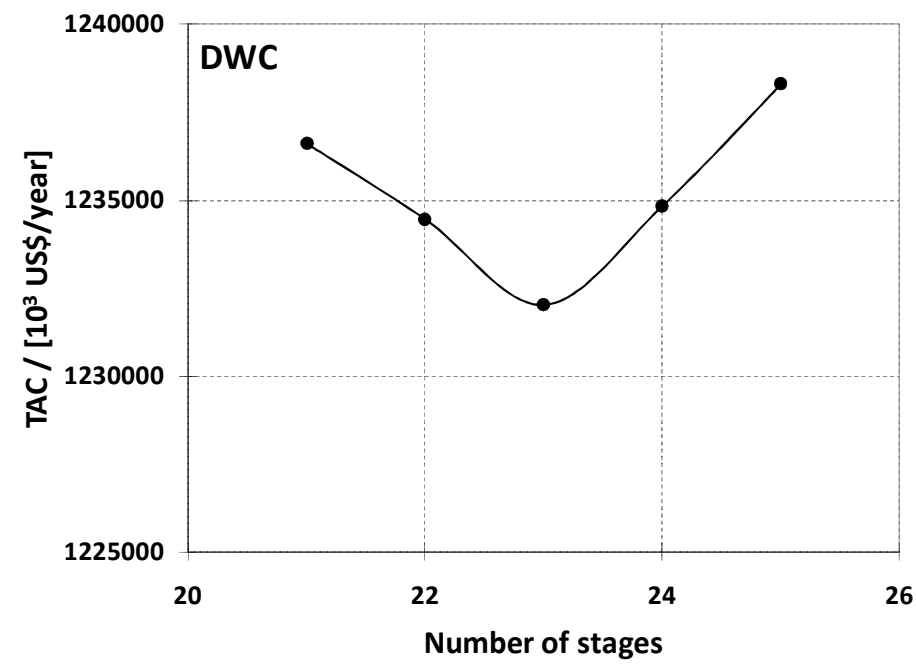

Figure 10. Total annual cost (TAC) optimization for the distillation columns 

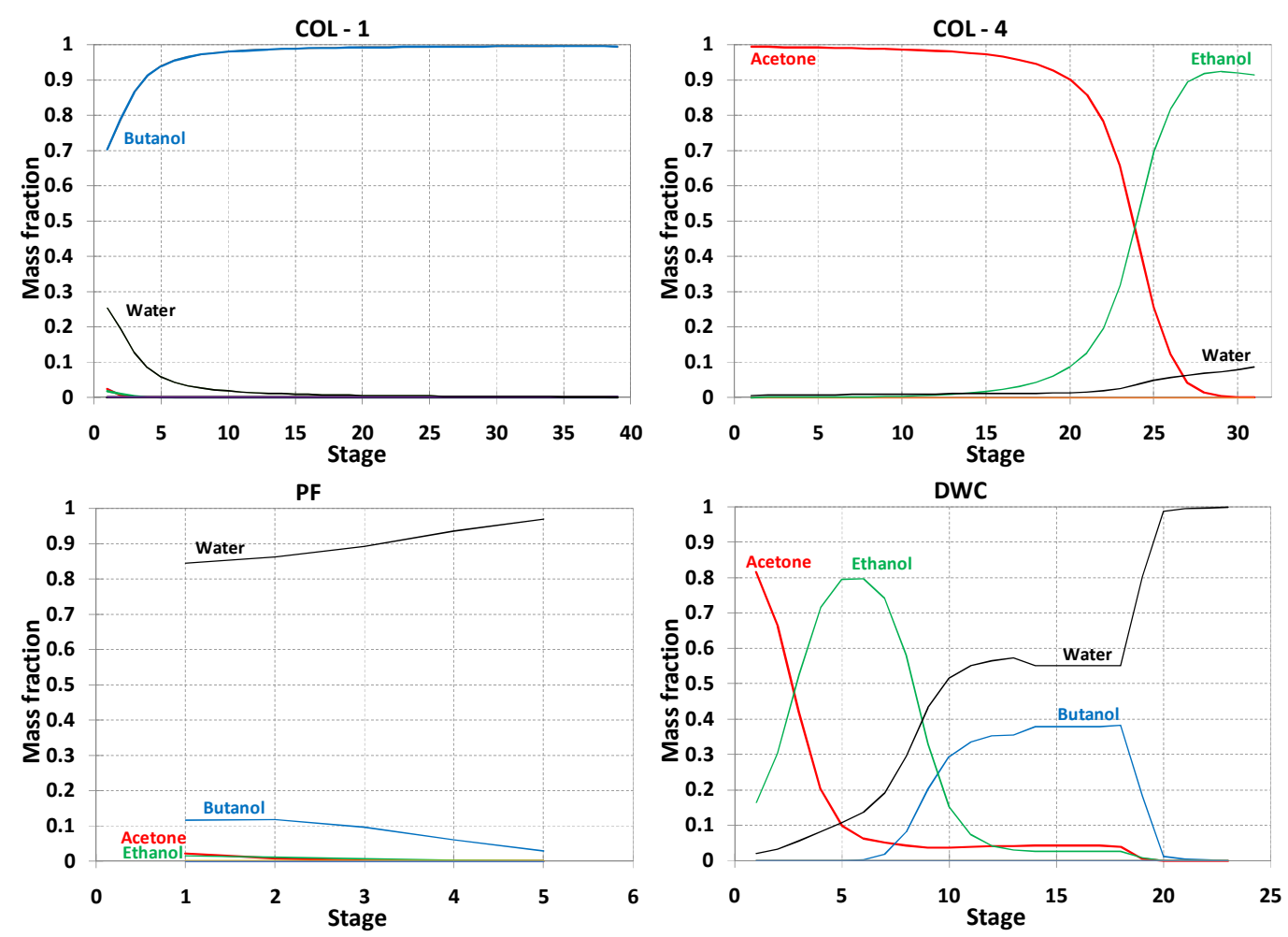

4

5

6

7

8

9

10

11

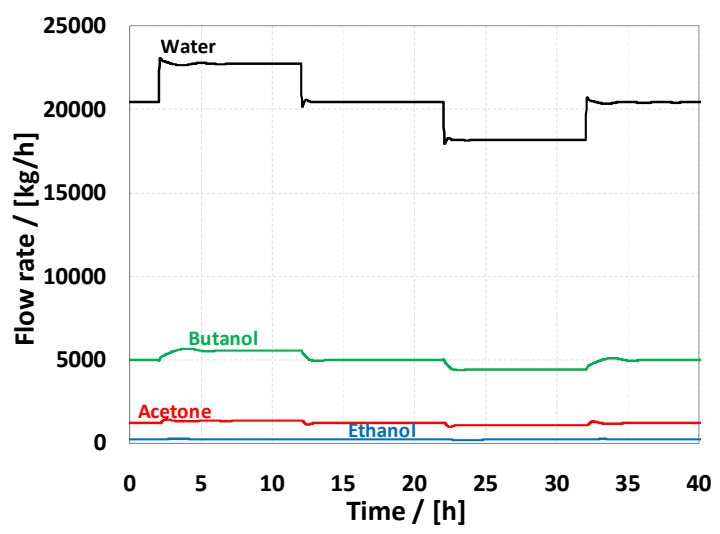

Figure 11. Mass composition profiles in the stripping, distillation columns and DWC

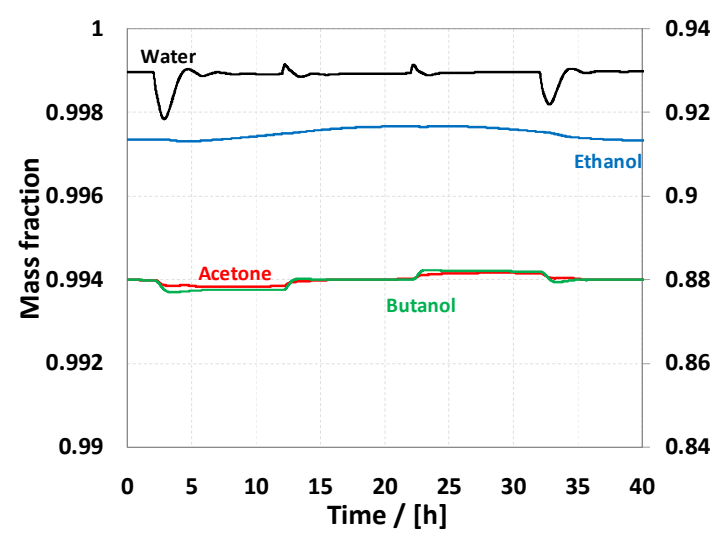

Figure 12. Dynamic simulations results (flow driven): flow rates (left) and composition (right) 


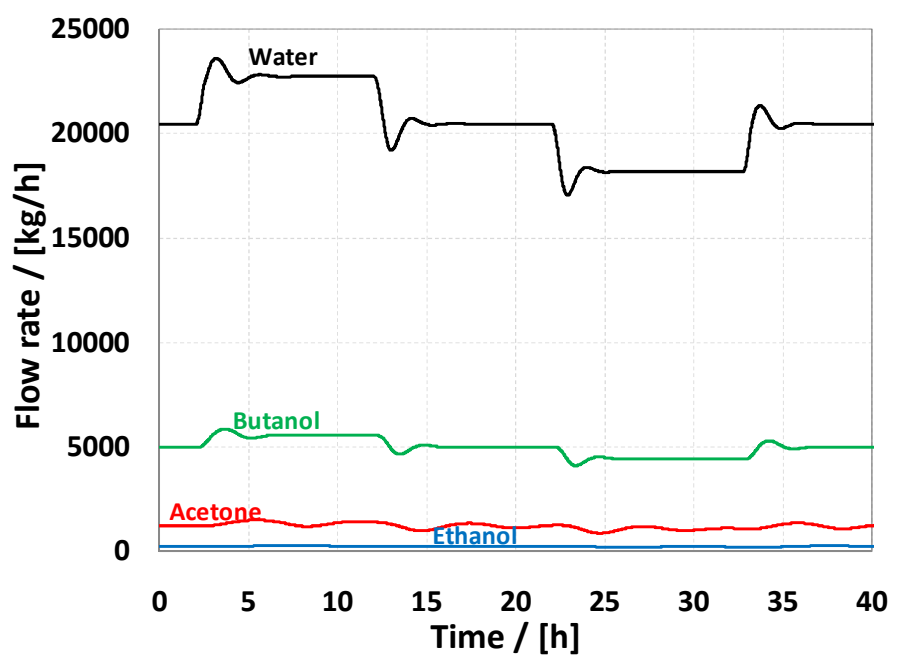

4
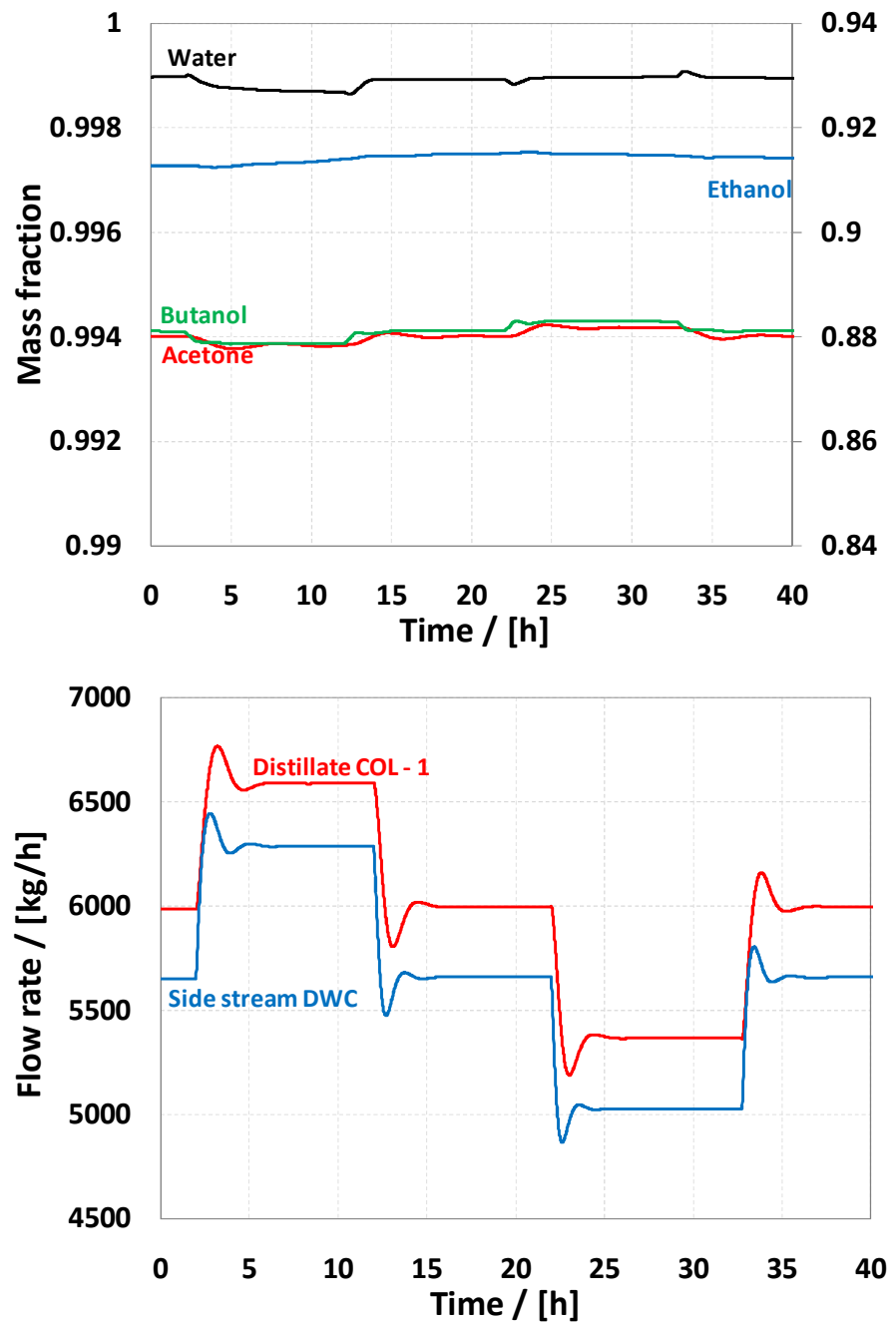

Figure 13. Dynamic simulations results (pressure driven) - feed flow rate disturbance 


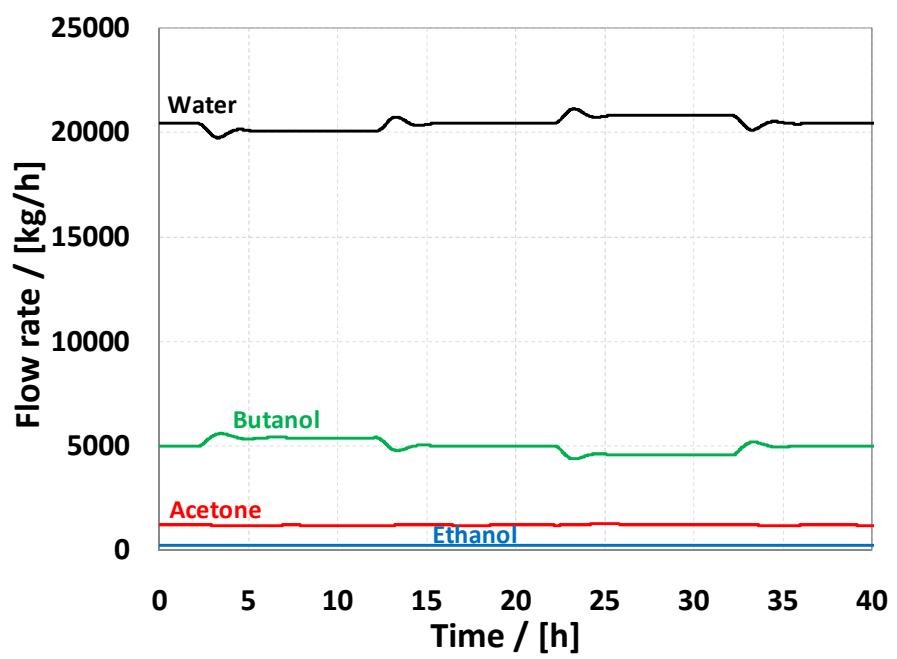

3

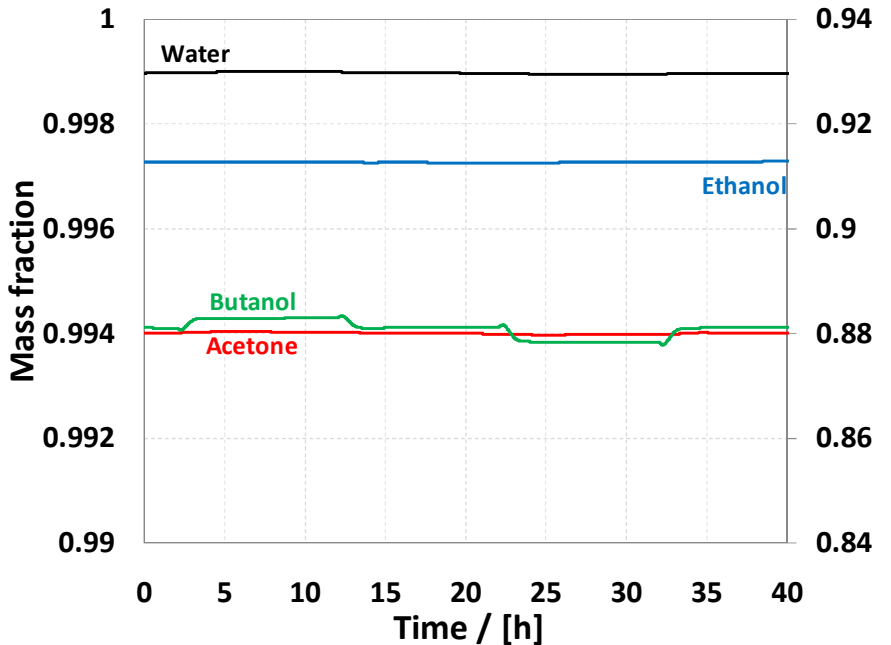

4

5

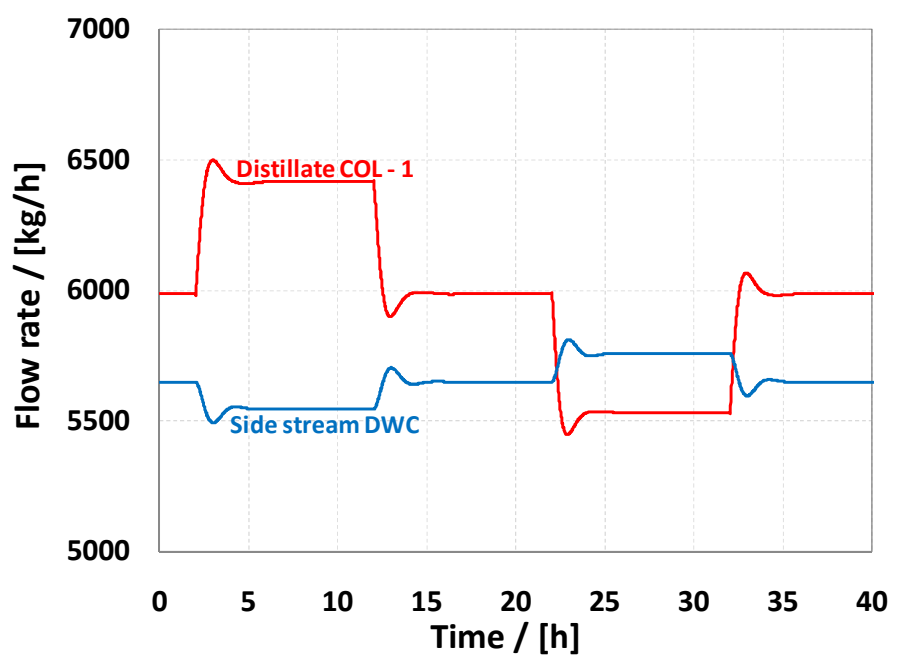

Figure 14. Dynamic simulations results (pressure driven) - butanol concentration disturbance 8 